\title{
EXTENSÃO UNIVERSITÁRIA E ORGANIZAÇÕES: A EXPERIÊNCIA DE ALUNOS DO CURSO DE ADMINISTRAÇÃO DA UNIVERSIDADE FRANCISCANA ${ }^{1}$
}

\author{
UNIVERSITY EXTENSION AND ORGANIZATIONS: \\ THE EXPERIENCE THE STUDENTS IN THE COURSE OF \\ ADMINISTRATION OF THE FRANCISCAN UNIVERSITY
}

\author{
Janaina Marchi ${ }^{2}$, Ana Carolina Cozza Josende da Silva ${ }^{3}$ e Juliana Rüdell Boligon ${ }^{4}$
}

\section{RESUMO}

Este trabalho teve como objetivo apresentar e discutir a experiência vivenciada a partir da disciplina extensionista Prática profissional II, do curso de Administração da Universidade Franciscana, ministrada no ano de 2020. A disciplina tem por propósito familiarizar o acadêmico com as realidades organizacionais distintas, no o intuito de contribuir com o aprimoramento da formação teórico-prática dos alunos e do desenvolvimento de capacidades, competências e habilidades projetadas em demandas advindas dos próprios territórios a partir do enfoque da gestão. O compartilhamento acadêmico de atividades desta natureza adquire relevância considerando o contexto pandêmico no qual as atividades vinculadas à disciplina foram realizadas. Em termos metodológicos, este trabalho configura-se como qualitativo e descritivo, do tipo relato de experiência, utilizando-se de fontes documentais como o Programa da disciplina, produtos realizados, relatórios docentes e evidências imagéticas provindas da atuação docente e discente. Entre os resultados apresentados neste texto, destaca-se a adaptação positiva ao formato remoto para cada uma das etapas previstas para que a interação alunos-território-sujeitos pudesse ser realizada. Ainda, destaca-se a efetividade na construção e entrega de produtos extensionistas com significância para alunos e territórios, apesar do distanciamento social e dos formatos virtuais de interação. Tais resultados evidenciam que a curricularização cumpriu seu papel de proporcionar aos estudantes o desenvolvimento de consciência cidadã em paralelo à formação técnica.

Palavras-chave: Extensão; Gestão; Pandemia Covid-19.

\footnotetext{
ABSTRACT

This work aimed to present and discuss the experience from the extensionist discipline Professional Practice II, from the Franciscan University Administration course, taught in 2020. The purpose of this discipline is to familiarize the academic with the different organizational realities, in the o in order to contribute to the improvement of the theoretical and practical training of students and the development of capacities, competences and skills projected in demands arising from the territories themselves, based on the management approach. The academic sharing of activities of this nature acquires relevance considering the pandemic context in which activities related to the discipline were carried out. In methodological terms, this work is characterized as qualitative and descriptive, of the experience report type, using documentary sources such as the discipline's Program, products produced, professors' reports and imagery evidence from the teaching and student activities. Among the results presented in this text, the positive adaptation to the remote format for each of the steps provided 1 Relato de experiência.

2 Graduada em História e Administração. Mestre em Administração. Professora da Universidade Franciscana. Email: janaina.marchi@ufn.edu.br

3 Graduada em Administração. Mestre em Engenharia da Produção. Doutoranda em Administração. Professora da Universidade Franciscana. Email: ana.carolina@ufn.edu.br

4 Graduada em Administração. Mestre em Engenharia da Produção. Email: julianarboligon@gmail.com
} 
for the student-territory-subject interaction can be highlighted. Still, the effectiveness in the construction and delivery of extension products with significance for students and territories stands out, despite the social distance and the virtual formats of interaction. These results show that curricularization fulfilled its role of providing students with the development of citizen awareness in parallel with technical training.

Keywords: Extension; Management; Covid-19 pandemic.

\section{INTRODUÇÃO}

A curricularização da extensão configura uma obrigatoriedade ao ensino superior a partir do texto do Plano Nacional de Educação 2014-2024, uma vez que, no entendimento apresentado nesse documento, não há indissociabilidade dos processos de ensino, pesquisa e extensão. Portanto, é fundamental que se encontrem caminhos que oportunizem a realização da extensão enquanto um processo de interação político, cultural, educacional transformador para as instituições de ensino superior e os outros setores da sociedade (BRASIL, 2018).

Considerando essa perspectiva, os cursos de graduação necessitam atualizar constantemente as ações educacionais a fim de que a interação necessária entre universidade e sociedade, por meio da prática extensionista, consiga promover resultados significativos para todos os agentes envolvidos nesse processo (DESLANDES; ARANTES, 2017).

O curso de Administração da Universidade Franciscana, ao oportunizar ao estudante a realização da extensão por meio da disciplina de Prática profissional II, cria espaços para que os diálogos, reflexões e ações sejam construídas tendo por base o propósito da extensão coadunado ao objetivo da disciplina: familiarizar o acadêmico com as realidades organizacionais distintas, com o intuito de contribuir com o aprimoramento da formação teórico-prática dos alunos, e do desenvolvimento de capacidades, competências e habilidades projetadas em demandas advindas dos próprios territórios.

Ademais, por meio das atividades realizadas, contribui-se com a disseminação do entendimento acerca da importância de se compreender e aplicar, de forma correta, ferramentas de gestão com vistas a solucionar problemas concernentes ao cotidiano dos territórios envolvidos com as disciplinas, sobretudo, no que diz respeito à forma como esses espaços são administrados.

$\mathrm{Na}$ atual conjuntura, percebe-se a importância que as organizações assumem perante o desenvolvimento das sociedades, uma vez que suas atuações impactam fortemente o modo de vida, considerando sobretudo, aspectos econômicos, culturais, ambientais e tecnológicos. Assim, formar gestores conscientes dessa responsabilidade, torna-se processo fundamental para o alcance de sociedades mais justas e equilibradas. Nesse ínterim, percebe-se a importância da extensão enquanto elemento qualificador do processo formativo nos cursos de Administração.

Um dos aspectos mais relevantes a ser considerado, diz respeito à diversificação dos espaços de atuação do gestor, enquanto um agente capacitado pensar as organizações, conhecendo a dinâmica 
organizacional, a estrutura da organização e suas várias possibilidades, tendo a possibilidade, assim, de influenciar de forma consciente e eficaz nas decisões (MINTZBERG; QUINN, 2001).

A partir dessa observação, é fundamental que os cursos de Administração se dediquem na busca por territórios não circunscritos apenas ao ambiente corporativo para a realização das ações extensionistas. Com essa compreensão em foco, estabeleceu-se uma parceria entre o curso de Administração da Universidade Franciscana e a Secretaria Municipal de Educação (SMED), mais especificamente, as escolas da rede pública municipal da cidade de Santa Maria. Esta parceria está firmada há mais de dois anos, e o curso de Administração, por meio de suas disciplinas extensionistas, consegue prestar auxílio na construção de soluções a problemas concernentes a seu escopo de atuação, concentrando-se na temática da gestão escolar.

A realização deste artigo é um passo importante no sentido de compartilhar os resultados obtidos com a Prática profissional II e, dentro de um escopo maior, no compartilhamento da experiência extensionista em um curso de Administração. Concernente a isso, estabeleceu-se com objetivo geral deste trabalho apresentar e discutir a experiência vivenciada a partir da disciplina extensionista Prática profissional II, do curso de Administração da Universidade Franciscana, dentro do recorte temporal do ano de 2020, primeiro ano de Pandemia Covid-19.

Como papel da disciplina extensionista do curso, tem-se como procedimento natural, ouvir, primeiramente, os sujeitos dos territórios, para, posteriormente, identificarem-se as demandas e, a partir disso, essas demandas são visualizadas dentro do contexto da gestão. Realizadas essas etapas, os alunos são desafiados a buscarem soluções, nas mais diferentes áreas da Administração, por meio de ferramentas capazes de gerarem os resultados esperados. No recorte temporal considerado para esta análise, o enfoque se deu nas áreas de Gestão financeira, Gestão de processos, Gestão de pessoas e Controle de estoques.

\section{CURRICULARIZAÇÃo DA EXTENSÃo}

A prática extensionista remonta suas origens à Inglaterra do século XIX, com a proposta de direcionar novos caminhos para a sociedade e promover a educação continuada. Hoje, é considerada um instrumento a ser utilizado pela Universidade para a efetivação do seu compromisso social e essa percepção ganha força a partir da década de 1960, quando surgiram ações de compromisso com as classes populares em prol de conscientizá-las sobre seus direitos (RODRIGUES et al., 2013). É correto dizer que este amadurecimento da Universidade para o seu compromisso com o social é fruto também, da atuação dos movimentos sociais, principalmente, da União Nacional dos Estudantes (UNE) que, ainda na década de 1960 coloca em curso o programa UNE Volante, o qual percorreu o país estabelecendo debates sobre a reforma universitária no conjunto das reformas de base propostas pelo governo João Goulart (DAYANE, 2018). 
O golpe civil-militar de 1964 coloca os movimentos sociais em período de hibernação e somente na década de 1980, observa-se uma retomada das discussões sobre a democratização do acesso ao ensino superior. No que diz respeito à extensão, o ano de 1987 é de vital importância, pois traz como marca a criação do Fórum Nacional de Pró-Reitores de Extensão das Universidades Públicas Brasileiras - hoje "Fórum de Pró-Reitores de Extensão das Instituições de Educação Superior Públicas Brasileiras" - o FORPROEX (NOGUEIRA, 2000).

Participaram do Fórum e da redação do documento final, intitulado "Conceito de extensão, institucionalização e financiamento”, 33 universidades públicas do país. O evento fortaleceu a importância da realização da extensão e foi incentivador das ações desenvolvidas posteriormente, dentre as quais destacam-se a curricularização da extensão nos anos 2000.

Ao observar o exposto no documento advindo do FORPROEX na década de 1980, percebe-se uma leitura atual acerca do propósito da extensão universitária enquanto uma prática dialética capaz de conjugar ensino, pesquisa e transformação social. Avaliação esta, encontrada em Silva (2011), que corrobora afirmando que a relação da universidade com a comunidade se fortalece pela e com a prática da extensão, ao proporcionar diálogo e a possibilidade de desenvolver ações socioeducativas.

Neste contexto, a curricularização da extensão faz parte do horizonte legal presente na Constituição brasileira de 1988 (Artigo 207) e na Lei de Diretrizes e bases da educação (LDB/96), que entende a indissociabilidade do ensino, da pesquisa e da extensão nas práticas pedagógicas de todos os currículos. Além, é claro, da necessária conexão da universidade com a sociedade, realçando o papel social da universidade, bem como a relevância social do ensino e da pesquisa (GADOTTI, 2017).

A partir do exposto, percebe-se que a prática da extensão (independentemente de seu viés assistencialista ou não assistencialista) e a luta para que seu lugar seja respeitado nas Universidades não é recente. O que observa-se, mais contemporaneamente, diz respeito aos esforços em integrar a extensão como uma função permanente e contínua, não dependente de ações isoladas e pontuais, em suma, a curricularização da extensão. Em linhas gerais, isso significa dar corpo ao conceito de integralidade da educação (ANTUNES; PADILHA, 2010), a qual requer um olhar que atenda às prerrogativas do ensino, da pesquisa e da extensão, em todo o seu transcurso.

Não obstante, conforme Gadotti (2017), ideia da curricularização da extensão é mencionada já no Plano Nacional de Educação (PNE) 2001-2010 (Metas 21 e 23), por meio do qual institui a "obrigatoriedade de $10 \%$ dos créditos curriculares exigidos para a graduação, integralizados em ações extensionistas".

A obrigatoriedade dos 10\% de créditos destinados à extensão reaparece no PNE 2014-2024 (Meta 12) acrescida do seguinte texto: “assegurar, no mínimo, 10\% (dez por cento) do total de créditos curriculares exigidos para a graduação em programas e projetos de extensão universitária, orientando sua ação, prioritariamente, para áreas de grande pertinência social” (BRASIL, 2014). Percebe-se forte apelo à formação cidadã, como um dos resultados esperados com as ações extensionsitas. 
Realizar a curricularização da extensão é um desafio às instituições de ensino superior brasileiras, uma vez que requer o repensar das concepções sobre o que é educação, o próprio currículo e o papel da universidade na sociedade (IMPERATORE; IMPERATORE, 2015). Nessa seara, torna-se imperativo revisitar o lugar, até então, ocupado pelo processo formativo do aluno, centrado em uma interação dicotomizada entre teoria-prática e, muitas vezes, realizado em um contexto reduzido com ganhos unilaterais e privados. O resultado desse processo deve corroborar um olhar ampliado onde inclui-se a perspectiva de movimento formador e interdisciplinar em articulação permanente com o ensino e a pesquisa (BRASIL, 2018).

O como fazer a curricularização não possui uma fórmula certa e, por ser uma demanda relativamente recente, requer muita reflexão. Neste ponto, o compartilhamento de experiências torna-se uma ferramenta para estimular o olhar crítico e reflexivo no sentido em que apresenta os caminhos percorridos em diferentes realidades. Este é o pensamento que motiva a realização deste trabalho.

\section{METODOLOGIA}

Em termos metodológicos, este trabalho configura-se como qualitativo e descritivo, do tipo relato de experiência, utilizando-se de fontes documentais como o Programa da disciplina, produtos realizados, relatórios docentes e evidências imagéticas provindas da atuação docente e discente.

Minayo (2010) argumenta que a pesquisa qualitativa responde a questões muito particulares e se ocupa, nas Ciências Sociais, com um nível de realidade que não pode ou não deveria ser quantificado. Esse formato de pesquisa trabalha com conjunto de fenômenos humanos (significados, dos motivos, das aspirações, das crenças, dos valores e das atitudes) que configuram parte da realidade social, uma vez que o ser humano se distingue não só por agir, mas pensar sobre o que faz e por interpretar suas ações dentro e a partir da realidade vivida e partilhada com seus semelhantes. Deste modo, a abordagem qualitativa oferece uma ampla e progressiva compreensão do processo de análise, da sua subjetividade e do simbólico, trazendo à tona aspectos da realidade que extrapolam a quantificação (MINAYO, 2010). Quando se tem como propósito apresentar a vivência em uma dada situação, o caminho mais aconselhável, portanto, perpassa o subjetivo capaz de ser acessado pelo estudo qualitativo.

O relato de experiência é um texto que descreve uma dada experiência capaz de contribuir de forma relevante para sua área de atuação. É a descrição de uma vivência exitosa ou não, mas que contribua com a discussão, a troca e a proposição de ideias para a melhoria do cuidado na saúde (MENESES, 2014). Percebe-se a adequação deste tipo de recurso de escrita quando se observa o objetivo deste trabalho.

As fontes para a pesquisa partiram das evidências geradas com o desenvolvimento da própria disciplina. Foram considerados documentos como: Plano de ensino e o projeto da disciplina, a fim 
de que as etapas consecutivas do trabalho realizado pudessem ser identificadas; o relatório final e as gravações dos encontros/aulas online, que permitiram contextualizar os impactos e resultados obtidos sob a luz da teoria pesquisada. O Plano de ensino é um documento fundamental para que seja possível visualizar o sequenciamento de atividades programados ao longo do período letivo em questão. Já o projeto da disciplina, é uma exigência da Universidade em questão sendo que neste documento, são apresentados os elementos que caracterizam a ação extensionista: territórios, sujeitos, objetivos, justificativa. O relatório final é um documento rico uma vez que descreve, sob o ponto de vista do professor, todo percurso da disciplina, podendo conter depoimentos de alunos sobre a experiência e o aprendizado alcançados.

A disciplina foi ministrada entre os meses de março e julho de 2020, portanto, a quase totalidade das ações realizadas estiveram no contexto de isolamento social provocado pela Pandemia Covid-19.

\section{RESULTADOS E DISCUSSÕES}

O objetivo deste trabalho consistiu em apresentar e discutir a experiência vivenciada a partir da disciplina extensionista Prática profissional II, do curso de Administração da Universidade Franciscana, ministrada no ano de 2020.

Para tanto, como primeiro resultado que proporciona o alcance deste objetivo proposto, construiu-se o Quadro 1 a seguir, o qual contempla de maneira objetiva, o sequenciamento das etapas realizadas no decorrer disciplina. A visualização destas etapas é positiva pois favorece o entendimento acerca dos momentos oportunizados desde o contato inicial com estudantes e a sensibilização para a prática da extensão, até a devolutiva final ao território.

Quadro 1 - Etapas desenvolvimentos das atividades

\begin{tabular}{|l|l|l|}
\hline \multicolumn{1}{|c|}{ OBJETIVO } & \multicolumn{1}{|c|}{ ATIVIDADE } & \multicolumn{1}{c|}{ DESCRIÇÃO } \\
\hline $\begin{array}{l}\text { Sensibilização sobre a } \\
\text { extensão e seu papel na } \\
\text { formação do aluno } \\
\begin{array}{l}\text { Sensibilização sobre } \\
\text { extensão }\end{array}\end{array}$ & $\begin{array}{l}\text { Aula presencial realiza- } \\
\text { da antes do isolamento } \\
\text { social }\end{array}$ & $\begin{array}{l}\text { Leitura dirigida } \\
\text { Giscussão pautada na proposta do PNE 2014-2024 bem como, no texto de }\end{array}$ \\
& $\begin{array}{l}\text { Foi disponibilizado aos alunos um artigo sobre “A CONTRIBUIÇÃO DA } \\
\text { EXTENSÃO UNIVERSITÁRIA NA MEDIAÇÃO ENTRE O TERRI- } \\
\text { TÓRIO E A POLÍTICAS PÚBLICAS" de Reidel et al (2015). A leitura } \\
\text { teve como prerrogativa instigar o aluno um pensamento crítico-reflexivo } \\
\text { em relação a extensão na disciplina, e um posicionamento do que espera e } \\
\text { como poderá contribuir no território que será atingido. }\end{array}$ \\
\hline $\begin{array}{l}\text { Levantamento de } \\
\text { demandas do território } \\
\text { - SMED }\end{array}$ & professoras da SEMD & $\begin{array}{l}\text { Para que as demandas do território pudessem ser melhor compreendidas, } \\
\text { professoras trabalhadoras da SMED foram até a Universidade, e compartilha- } \\
\text { ram relatos, experiências, necessidades e, a partir disso, algumas demandas } \\
\text { puderam ser identificadas e, dentro dessas demandas levantadas, delinearam-se } \\
\text { possibilidades de desenvolvimento dos trabalhos, nas áreas de Gestão de pes- } \\
\text { soas, Gestão de processos, Gestão financeira e Controle de estoque. }\end{array}$ \\
\hline
\end{tabular}




\begin{tabular}{|c|c|c|}
\hline $\begin{array}{l}\text { Apropriação teórica } \\
\text { acerca da temática } \\
\text { principal }\end{array}$ & Leitura dirigida & $\begin{array}{l}\text { Após a roda de conversa com as professoras da SMED, foram disponi- } \\
\text { bilizados aos alunos, artigos, os quais foram lidos de acordo com roteiro } \\
\text { elaborado pelas professoras. A elaboração do roteiro para orientar a leitura } \\
\text { teve como prerrogativa, instigar o pensamento crítico-reflexivo sobre o } \\
\text { contexto escolar e a gestão escolar, sobretudo, a gestão democrática. }\end{array}$ \\
\hline $\begin{array}{l}\text { Apropriação teórica } \\
\text { acerca da temática } \\
\text { principal }\end{array}$ & $\begin{array}{l}\text { Análise de } \\
\text { documentário }\end{array}$ & $\begin{array}{l}\text { Consoante ao processo de apropriação teórica da temática e do território, } \\
\text { desenvolveu-se, junto aos alunos, a atividade de análise do documentário: } \\
\text { QUANDO SINTO QUE JA SEI (2014). A análise consistiu em uma parte } \\
\text { técnica (roteiristas, direção, ano de produção), e uma análise do conteúdo } \\
\text { do documentário, buscando, a partir de gatilhos e questionamentos apre- } \\
\text { sentados pelas professoras em um roteiro, instigar os alunos a identificarem } \\
\text { semelhanças nas realidades retratadas pelos atores e a realidade apresenta- } \\
\text { da a eles, na fala das professoras da SMED. }\end{array}$ \\
\hline $\begin{array}{l}\text { Construção dos } \\
\text { Planos de Ação }\end{array}$ & $\begin{array}{l}\text { Redação dos planos e } \\
\text { propostas de ação }\end{array}$ & $\begin{array}{l}\text { Encerradas as etapas de sensibilização e apropriação teórica, os alunos } \\
\text { dedicaram-se a construírem, em grupos de } 3 \text { alunos, objetivos geral e espe- } \\
\text { cíficos para cada proposta a ser desenvolvida ao longo das aulas. }\end{array}$ \\
\hline $\begin{array}{l}\text { Construção dos } \\
\text { relatórios }\end{array}$ & & $\begin{array}{l}\text { A estrutura dos relatórios contemplou uma introdução; referencial teórico; } \\
\text { desenvolvimento da proposta e conclusão. }\end{array}$ \\
\hline Devolutiva ao território & Live com a SMED & $\begin{array}{l}\text { Para finalizar o ciclo da extensão, foi realizada a live de encerramento das } \\
\text { atividades, onde os principais resultados construídos pelos grupos foram } \\
\text { apresentados. }\end{array}$ \\
\hline
\end{tabular}

Fonte: elaborado pelas autoras

Utilizando-se da metodologia apresentada no Quadro 1, no primeiro momento, foi realizada uma roda de conversa com as professoras e os alunos, com o objetivo apresentar o contexto da extensão universitária a partir do enfoque manifestado no PNE 201-2024, Meta 12. Além disso, estabeleceu-se um diálogo com os estudantes acerca do propósito e importância da realização da curricularização da extensão a partir de leituras de textos cujas temáticas corroboraram o entendimento do Plano Nacional de Educação atual. Esse momento foi fundamental para a desconstrução e construção de perspectivas acerca do papel não assistencialista da extensão, e da sua compreensão como uma prática transformadora da sociedade.

Logo após, os alunos tiveram contato com representantes do território escolhido para a prática da disciplina: a Secretaria de Educação de Santa Maria - SMED. O diálogo teve o intuito de conhecer a realidade da gestão escolar do município e as demandas das escolas da cidade. Este contexto é algo bastante específico, distanciando-se do que se apresenta como um território habitual a um aluno de um curso de Administração: empresas privadas. Além disso, poucas vezes em sua formação, o estudante consegue imergir em um ambiente organizacional distinto. Dessa forma, este primeiro contato com a realidade do território, foi instigante e esclarecedora aos alunos.

A partir disso, foi possibilitado o entendimento de possíveis demandas, às quais foram discutidas com as professoras da disciplina e demais colegas, considerando também, leituras que proporcionaram base teórica sobre a abordagem da gestão escolar, a partir da leitura dirigida de estudos de casos, artigos e análise fílmica. Ressalta-se que a utilização de elementos diversos para instigar o aluno apresentou-se como algo essencial para o engajamento na realização dos trabalhos. 
Superadas estas etapas, os alunos organizaram-se em grupos de trabalho, por afinidade pessoal e afinidade de tema. Ainda, validou-se juntamente ao território, as demandas identificadas pelos estudantes, as quais, posteriormente, transformaram-se em temáticas para a ação junto aos sujeitos. Essas temáticas, versaram sobre: gestão de estoques, fluxo de caixa, perfil de liderança da gestão, motivação, mapeamento de processos e comunicação. Com isso, procurou-se oferecer um suporte à SMED, mas também, às escolas, pois as ações desenvolvidas foram capazes de atender à problemáticas percebidas dentro destes diferentes contextos.

Para que o trabalho pudesse tornar-se palpável, a ferramenta pedagógica utilizada foi a construção de relatórios. Nestes relatórios, cujas seções dividiram-se em Introdução; Referencial teórico; Desenvolvimento da proposta e Conclusão, a temática da ação foi abordada em contexto teórico, considerando o aprofundamento requerido para que os alunos pudessem desenvolver melhor suas práticas junto aos sujeitos do território (seções Introdução e Referencial teórico). Da mesma forma, na seção Desenvolvimento da proposta, construíram-se os planos com o detalhamento de cada sequência de ação que caracterizou as práticas. Nesta seção, os alunos ocuparam-se ainda de construir uma explicação acerca da ferramenta de gestão sugerida, formas de utilizá-la, pois o intuito é que o processo seja executado pelos professores e trabalhadores da SMED, sem necessidade de suporte por parte dos alunos. A Conclusão foi a última seção a ser construída (após a devolutiva ao território), e apresentou as percepções, sentimentos e aprendizados dos alunos com a disciplina.

Diante das propostas de trabalho construídas pelos grupos, foi agendada uma live com representantes da Secretaria Municipal de Educação. Este momento configura-se como um dos mais relevantes ao processo extensionista, pois faz referência à devolutiva ao território e ao feedback dos sujeitos frente ao resultado apresentado.

Nesta live, foi possível a interação dos alunos com a SMED, contribuindo para atingir o objetivo da extensão com o compartilhamento do conhecimento e o equilíbrio entre as demandas da sociedade e os saberes e inovações produzidos pelo trabalho de docentes e estudantes (SILVA, VASCONCELOS, 2004). Este diálogo foi fundamental para os alunos compreenderem a relevância social do trabalho realizado e os auxiliou com insights para a conclusão do plano apresentado no relatório da disciplina.

Com o relatório concluído, os grupos gravaram vídeos em formato de tutoriais, para a aplicação dos planos construídos ao longo da disciplina, tais vídeos, juntamente com os relatórios completos, foram disponibilizados pelas professoras ministrantes para a Secretaria de Educação do Município para serem utilizados como ferramentas de gestão, com o intuito de agregar valor ao trabalho efetivo já realizado por esta Secretaria.

$\mathrm{O}$ principal ponto que requer atenção, diz respeito à disparidade dos trabalhos realizados pelos alunos, em que foi possível observar que em alguns grupos, houve o engajamento efetivo com o propósito da disciplina. Em outros, o contexto de isolamento social foi apontado como um dificultador do sentimento de empatia para com os sujeitos e territórios e justificador para a realização de 
trabalhos mais modestos. Nesses termos cabe a reflexão sobre que outras formas dentro do contexto pandêmico, podem ser utilizadas como meios capazes de proporcionar essa imersão e aproximação dos estudantes com a sociedade ou com territórios que podem ser alheios à realidade dos discentes.

Contudo, acredita-se que a experiência da disciplina, hora retratada, corrobora o entendimento da extensão como um processo que permeia o ensino e a pesquisa, integrando essas atividades, a qual deve ser parte indispensável da rotina universitária, institucionalizando-se tanto do ponto de vista administrativo como da prática acadêmica.

\section{CONCLUSÃO}

A extensão universitária, em sua proposta de curricularização, já é por si só, um grande desafio. Em tempos de Pandemia e isolamento social, configura-se em um desafio ainda maior, pois limita, sobretudo, a inserção no campo, o contato direto com os sujeitos. Esse cenário foi o catalizador de uma transformação profunda no campo educacional e também, dos caminhos encontrados para realizar a extensão.

A curricularização da extensão requer a institucionalização desse processo, e isso pressupõe uma estrutura de apoio e suporte para a materialização dessa demanda. Por isso, é fundamental que a Universidade crie mecanismos capazes de colocá-la em curso, oportunizando aprendizado e amadurecimento aos docentes e discentes. Nesse ínterim, cabe salientar a importância de os cursos terem uma coordenação de extensão e uma referência central, a nível institucional, capaz de acompanharem a realização do trabalho em cada disciplina. Isso é um ponto forte observado na Universidade Franciscana.

Outro fator a ser destacado diz respeito à espaços de discussão, reflexão e formatação das experiências extensionistas, como é o caso do espaço concedido em revistas acadêmicas que contemplem esse escopo.

Então, entende-se que fazer extensão é um processo coletivo, que requer o envolvimento de diferentes agentes sem preterir uma estrutura acadêmica capaz de oferecer as condições fundamentais para que o processo seja executado, em todas as suas etapas.

O compartilhamento de informações e experiências atua como uma ferramenta de aprendizagem coletiva, no sentido em que professores e comunidade podem acessar de maneira sistemática, os resultados e o percurso da extensão no contexto das instituições de ensino superior. Assim sendo, observa-se que as atividades realizadas na disciplina de Prática profissional II, do curso de Administração da Universidade Franciscana, além de contemplarem o entendimento acerca da extensão enquanto um processo capaz de gerar impactos positivos e transformadores junto aos territórios envolvidos, ainda soma no sentido de apresentar em formato de artigo sua trajetória, a fim de que se gere, a partir disso, novas discussões capazes de fortalecer e melhorar ainda mais, as ações já realizadas. 
A partir dos que exposto na seção anterior, foi possível perceber que as atividades puderem ser realizadas, com ajustes e adaptações necessárias. Os professores conseguiram encontrar maneiras de driblar as adversidades, e estimular diálogos que pudessem deixar vir à tona, as demandas latentes da sociedade, uma vez que, sem a comunidade, não há extensão. É evidente que as atividades extensionistas configuram um olhar para fora, mas também, um olhar para “dentro", pois, dentre as inúmeras demandas que existem e que são reais nos territórios, é preciso que a Academia compreenda claramente o seu papel, seus limites, e defina até onde pode intervir, a fim de que haja troca, verdadeira

Com a finalização do projeto, pode-se afirmar quer houve uma aproximação do ambiente acadêmico e a comunidade, vivenciados pelos alunos com a oportunidade de aumentar seus conhecimentos relacionados aos temas de gestão.

Os resultados mostram o compartilhamento de conhecimentos entre acadêmicos e instituições, onde essas últimas disponibilizam informações, compartilham seus pontos fracos em troca de um diagnóstico e sugestões que otimizem seus processos administrativos, possibilitando aos alunos construírem novas bases societárias, visando atender a um mercado de trabalho que demanda profissionais que farão parte de diversos espaços sociais.

Desta forma, as práticas de extensão possibilitam aos acadêmicos a operacionalização das competências desenvolvidas no respectivo curso de formação que visem ao bem comum das pessoas para promover mudanças na sociedade e na Universidade.

\section{REFERÊNCIAS}

Brasil. Resolução CNE/CES 7/2018. Diário Oficial da União, Brasília, 19 de dezembro de 2018, Seção 1, p. 49-50.

BRASIL. Constituição da República Federativa do Brasil. Brasília, DF: Senado Federal: Centro Gráfico, 1988.

GADOTTI, Moacir. Extensão Universitária: para quê? 2017. Disponível em: https://bit.ly/2XqPXvB. Acesso em: 20 out. 2020.

MINTZBERG, H.; QUINN, J. B. O processo da estratégia. Porto Alegre: Bookman, 2001, 271-282.

IMPERATORE SLB, Pedde V, IMPERATORE JLR. Curricularizar a extensão ou extensionalizar o currículo? Aportes teóricos e práticas de integração curricular da Extensão ante a estratégia 12.7 do PNE.” In: XV COLÓQUIO INTERNACIONAL DE GESTÃO UNIVERSITÁRIA - CIGU, Argentina, 2015. 
NARDI, Elton Luiz. Gestão democrática do ensino público na educação básica: dimensões comuns e arranjos institucionais sinalizados em bases normativas de sistemas municipais de ensino. Educa em Revista, 2018, v. 34, n. 68, p. 123-136.

PARO, Vitor Henrique. A educação, a política e a administração: reflexões sobre a prática do diretor de escola. Revista Educação e Pesquisa, 2010, v. 36, n. 3, p. 763-778.

RODRIGUES, A. L. L.; PRATA, M. S.; BATALHA, T. B. S.; COSTA, C. L. N. Do A.; NETO, I. F. P. Contribuições da extensão universitária na Sociedade. Cadernos de Graduação - Ciências Humanas e Sociais, Aracaju. v. 1. n. 16. p. 141-148. mar. 2013. Disponível em: https://bit.ly/ 30IHNjB. Acesso em: 20 out. 2020.

SILVA, Valéria. Ensino, pesquisa e extensão: Uma análise das atividades desenvolvidas no GPAM e suas contribuições para a formação acadêmica. Vitória, novembro de 2011. Base de dados do Scielo. Disponível em: https://bit.ly/3ncQ6f9. Acesso em: 20 out. 2020.

SILVA, M. S; VASCONCELOS, D.S. Perfil das Atividades Extensionistas do Centro de Ciências Biológicas da Universidade Federal de Pernambuco. In: CONGRESSO BRASILEIRO DE EXTENSÃO UNIVERSITÁRIA, 2. Anais... Belo Horizonte, 2004.

QUANDO sinto que já sei. Direção de Anderson Lima, Antonio Lovato e Raul Perez. Despertar Filmes, 2014. (78 min.) 